\title{
Emerging and Adjunctive Therapies for Spinal Cord Injury Following Acute Canine Intervertebral Disc Herniation
}

\author{
Melissa J. Lewis ${ }^{1 *}$, Nicolas Granger ${ }^{2,3 \dagger}$, Nick D. Jeffery ${ }^{4}$ and \\ the Canine Spinal Cord Injury Consortium (CANSORT-SCI)
}

OPEN ACCESS

Edited by:

Edward E. Patterson University of Minnesota Twin Cities,

United States

Reviewed by:

Franck Forterre

University of Bern, Switzerland Rodrigo Gutierrez-Quintana,

University of Glasgow, United Kingdom

*Correspondence:

Melissa J. Lewis

lewis444@purdue.edu

tThese authors have contributed equally to this work

Specialty section: This article was submitted to Veterinary Neurology and Neurosurgery,

a section of the journal

Frontiers in Veterinary Science

Received: 03 July 2020 Accepted: 04 September 2020 Published: 15 October 2020

Citation:

Lewis MJ, Granger N, Jeffery ND and the Canine Spinal Cord Injury Consortium (CANSORT-SCI) (2020) Emerging and Adjunctive Therapies for Spinal Cord Injury Following Acute Canine Intervertebral Disc Herniation.

Front. Vet. Sci. 7:579933.

doi: 10.3389/fvets.2020.579933
${ }^{1}$ Department of Veterinary Clinical Sciences, Purdue University College of Veterinary Medicine, West Lafayette, IN, United States, ${ }^{2}$ The Royal Veterinary College, University of London, Hertfordshire, United Kingdom, ${ }^{3} \mathrm{CVS}$ Referrals, Bristol Veterinary Specialists at Highcroft, Bristol, United Kingdom, ${ }^{4}$ Department of Small Animal Clinical Sciences, Texas A \& M College of Veterinary Medicine and Biomedical Sciences, College Station, TX, United States

Some dogs do not make a full recovery following medical or surgical management of acute canine intervertebral disc herniation (IVDH), highlighting the limits of currently available treatment options. The multitude of difficulties in treating severe spinal cord injury are well-recognized, and they have spurred intense laboratory research, resulting in a broad range of strategies that might have value in treating spinal cord-injured dogs. These include interventions that aim to directly repair the spinal cord lesion, promote axonal sparing or regeneration, mitigate secondary injury through neuroprotective mechanisms, or facilitate functional compensation. Despite initial promise in experimental models, many of these techniques have failed or shown mild efficacy in clinical trials in humans and dogs, although high quality evidence is lacking for many of these interventions. However, the continued introduction of new options to the veterinary clinic remains important for expanding our understanding of the mechanisms of injury and repair and for development of novel and combined strategies for severely affected dogs. This review outlines adjunctive or emerging therapies that have been proposed as treatment options for dogs with acute IVDH, including discussion of local or lesion-based approaches as well as systemically applied treatments in both acute and subacute-to-chronic settings. These interventions include low-level laser therapy, electromagnetic fields or oscillating electrical fields, adjunctive surgical techniques (myelotomy or durotomy), systemically or locally-applied hypothermia, neuroprotective chemicals, physical rehabilitation, hyperbaric oxygen therapy, electroacupuncture, electrical stimulation of the spinal cord or specific peripheral nerves, nerve grafting strategies, 4-aminopyridine, chondroitinase $\mathrm{ABC}$, and cell transplantation.

Keywords: alternative therapies, interventions, dog, intervertebral disc disease, cell transplantation, spinal cord injury, canine 


\section{INTRODUCTION}

Current treatment for acute canine intervertebral disc herniation (IVDH) can be divided into medical/conservative or surgical management. The decision as to which to pursue depends largely on the severity of neurologic signs. These might be due to either reversible or irreversible damage to the spinal cord itself, with some resulting from tissue ischemia that is difficult to counteract and others resulting from spinal cord compression that are easily reversible. Medical management commonly consists of activity restriction, pain, and anti-inflammatory medications. The goals are: (i) to avoid further disc herniation to minimize additional damage to the spinal cord; (ii) provide pain relief; (iii) allow the extruded disc material to gradually dissipate by phagocytosis over time; (iv) and leave the ruptured disc annulus to seal by fibrosis over time. Surgical intervention is used to alleviate persistent spinal cord compression. The reader is directed to the article, "Current approaches to the management of acute thoracolumbar disc extrusion in dogs" for more information regarding the evidence for the commonly applied treatment options.

Neither medical nor surgical management currently aim to repair the damaged intervertebral disc, nor heal the injured spinal cord, and there are limits to the recovery that can be attained. Severe injuries still result in incomplete recovery and unsatisfactory functional status. Although largely understandable, with restoration of function to spinal cord injured individuals recognized as a holy grail for centuries, this failure has prompted a vast effort in neuroscience research. The aim is to develop strategies that directly target the injury within the spinal cord, limit the extent of secondary injury, facilitate regeneration of axons, or increase compensatory plasticity of the surviving tissue. Many neuroprotective and neuro-regenerative therapies have shown promise in pre-clinical experimental models but few have made it beyond this phase and when they have, repeatedly failed to successfully translate to humans or dogs with naturally-occurring spinal cord injury (SCI) $(1,2)$. In fact, it has been reported that only about one-third of animal studies for any disease considered to have a high likelihood of translation into human medicine actually progressed to the clinical trial stage and even fewer were associated with any currently available intervention $(3,4)$. While this should not deter researchers and clinicians from seeking novel treatment options for the injured spinal cord, it does highlight the huge hurdles facing such work and underscores the difficulty of the problem. Importantly, knowledge of what has been done, successful or otherwise, is crucial to broadening our understanding mechanisms of injury and recovery, developing new techniques, or adapting and combining previously suggested treatment modalities for application to clinical populations.

This review will summarize adjunctive or emerging therapies that have been proposed as treatment options for dogs with acute IVDH. We will focus on data available from companion dogs with naturally-occurring SCI but also include data on experimental dogs where relevant. This is the information that we hope will be most useful to veterinary clinicians and might soon be applicable in the neurology clinic. We will focus on therapies that can be applied following acute SCI (within 1 month of injury) but also discuss therapies that might aid in repairing the spinal cord or restoring function in the subacute to chronic patient ( $>1$ month from injury). We have divided treatments in those delivered at or close to the injury site and those delivered systemically.

\section{ADJUNCTIVE THERAPIES IMPLEMENTED IN THE ACUTE PHASE}

\section{Local/Lesion-Based Interventions}

A variety of locally administered interventions have been proposed in the treatment of SCI that are applied directly to the lesion site in addition to, or in lieu of, decompressive surgery. These include laser therapy, application of electromagnetic fields or oscillating electrical fields, adjunctive surgical techniques, locally-applied spinal cord hypothermia, and cell transplantation. Cell transplantation strategies will be discussed in the subacute to chronic section in the second part of this review.

\section{Laser Therapy}

Low-level laser therapy or photobiomodulation has been a reported therapy for various injuries, including SCI. In the nervous system, it has been proposed to enhance neuronal metabolism and sprouting and to decrease glial scar formation and the immune response $(5,6)$. While not fully understood, the mechanisms of action are reported to include inhibition of NF-kB (which reduces expression of pro-inflammatory mediators) and stimulation of cytochrome oxidase (which might help to optimize oxidative metabolism) $(5,6)$. In an unblinded, unrandomized prospective study of non-ambulatory paraparetic or paraplegic dogs with IVDH, with or without intact pain perception at enrolment and treated surgically, laser therapy applied postoperatively (for 5 days or until independent ambulation was achieved) was compared to dogs that did not receive additional therapy. The reported time to achieve independent ambulation was shorter in the laser therapy group (3.5 days) compared to untreated control dogs (14 days) (7). However, the characteristics of the laser employed were not detailed making it difficult to try to replicate results. In contrast, a blinded, randomized prospective study evaluating post-operative laser therapy with or without physical rehabilitation in non-ambulatory dogs undergoing surgery for IVDH revealed no difference in recovery (8). Importantly, both studies included a relatively small number of dogs in each treatment group, including few with severe injury, did not incorporate pre-study sample size calculations, and only looked at short-term outcome variables. No adverse events attributable to laser therapy were reported.

\section{Electromagnetic and Electrical Field Therapies}

While application of a pulsed electromagnetic field (PEMF) device to the site of injury has been most widely studied in pain and wound repair, PEMF therapy has been reported to reduce back and neck pain in people and possibly improve recovery from SCI in an experimental model in cats (9-13). The mechanism of action of PEMF in pain relief is likely multifactorial and there is 
limited evidence in central nervous system injury that it can aid in promoting axonal regeneration or sparing of surviving axons $(9,10)$. In a recent blinded, randomized prospective clinical trial of paraplegic dogs with absent pain perception secondary to IVDH that underwent surgery, PEMF reduced post-operative incisional pain (as measured by increased mechanical sensory thresholds) compared to sham-treated control dogs. The authors also reported a possible neurologic benefit based on measuring injury severity using plasma GFAP concentration and recovery of proprioceptive placing (14). However, sample size was small and multiple outcomes were evaluated.

Oscillating electrical field therapy, which is suggested to enhance axonal regrowth and improve functional recovery, has been applied to spinal cord-injured animals (15). In paraplegic deep pain negative dogs secondary to IVDH treated surgically, oscillating electrical field therapy was delivered post-operatively via electrodes sutured to the edges of the laminectomy site and attached to an implantable device. Treatment was administered for a variable number of weeks post-operatively and the device and therapy were well-tolerated. Dogs treated with the electrical fields had improved neurologic outcomes at 6 weeks and 6 months after surgery compared with sham-treated dogs $(15,16)$. Despite initial promise, logistical, and technical issues hindered further development of this treatment modality.

\section{Local Hypothermia}

Locally-applied spinal cord hypothermia has been rarely reported as a treatment for SCI in dogs in experimental studies (17-20). Hypothermic conditions $\left(4-6^{\circ} \mathrm{C}\right)$ were applied to the spinal cord initiated at $15 \mathrm{~min}$ to $4 \mathrm{~h}$ after injury and maintained for variable durations ranging from 1 to $18 \mathrm{~h}$. In these studies, hypothermia was reported to improve functional outcome in experimentallyinjured dogs compared to untreated controls with a possible additive benefit in combination with other therapies. However, reported drawbacks included extensive technical and personnel demands, the potential for inadvertent damage to spinal cord through prolonged hypothermia and lack of information on long-term outcomes or sequelae (17). This technique has not been reported in dogs with naturally-occurring injury secondary to IVDH but mean body temperature was identified as an exploratory variable worthy of further evaluation in prospective studies in dogs with IVDH (21). Local and systemic hypothermia continue to be investigated in human medicine $(22,23)$.

\section{Adjunctive Surgical Techniques to Spinal Cord Decompression: Durotomy and Myelotomy}

The role and indications for decompressive surgery as well as fenestration as a standalone technique for acute IVDH are outlined in the companion article in this issue, "Current approaches to the management of acute thoracolumbar disc extrusion in dogs." Adjunctive surgical techniques of durotomy and myelotomy are summarized below.

Durotomy has been investigated as a means to decompress a swollen spinal cord, to improve spinal cord blood flow and oxygen delivery and to evaluate for gross myelomalacia as a prognostic indicator (24-27). Durotomy with or without duroplasty has been reported to have positive effects in multiple experimental rodent and human SCI studies; however, reported functional impact is variable, adverse effects are possible, and controlled studies are lacking (24). In experimental studies in dogs, immediate but not delayed (by $2 \mathrm{~h}$ ) durotomy was reported to enhance recovery rate and overall neurologic outcome $(25,27,28)$. In clinical canine patients, durotomy has typically been reserved for severely affected dogs. Blaser et al. demonstrated that durotomy combined with decompressive hemilaminectomy in dogs with IVDH (of varying severity ranging from ambulatory paraparesis to paraplegia with intact pain perception) transiently increased intraoperative spinal cord blood flow, although it returned to normal or lower within $15 \mathrm{~min}$ (26). There was no association detected between durotomy and 1 -day post-operative neurologic outcome. However, none of the included dogs were those that have the most to benefit from durotomy (i.e., those paralyzed with absent pain perception at presentation), thereby potentially limiting the generalizability of these results. In an additional retrospective study of 48 paraplegic dogs that were deep pain negative secondary to IVDH, no difference was detected in recovery of ambulation between those that did or did not receive a durotomy in conjunction with hemilaminectomy (29), although confounding by severity is a clear possibility in this study.

More recently, contrasting evidence has been provided by Takahashi et al. who reported on 116 paraplegic deep pain negative dogs with thoracolumbar IVDH treated with hemilaminectomy alone $(n=65)$ or hemilaminectomy plus durotomy $(n=51)$ (30). A large proportion of dogs recovered following durotomy vs. hemilaminectomy alone (56.9 vs. $38.5 \%$ ). The low rate of recovery in the non-durotomy group (compared to most published reports of a $50-60 \%$ success rate with decompressive surgery) was attributed to inclusion only of cases that had imaging features associated with poor prognosis. Notably, no dogs in the durotomy group compared to 14 in the hemilaminectomy-only group developed progressive myelomalacia. In another recent report, "extended durotomy" of four vertebral lengths centered over the site of herniation was also investigated in 26 consecutive paraplegic dogs that were deep pain negative secondary to thoracolumbar IVDH (31). Of the 26 dogs included in the study, 4 dogs were lost to follow-up while 16/22 remaining dogs recovered independent ambulation within 6 months (with 15/16 also recovering continence) (31). No adverse events were attributable to the extended durotomy; one dog developed progressive myelomalacia. These studies together reinvigorate the discussion as to whether durotomy might be beneficial in dogs with severe injury, especially in preventing development of progressive myelomalacia. Additional information is needed regarding single vs. extended durotomy, the role of duroplasty, patient selection among severely affected dogs, and the risk and functional impact of longterm consequences such as fibrosis that might negatively impact neurologic function.

Dorsal midline myelotomy has been reported as a treatment for SCI to decrease intramedullary pressure, increase the oxygen interface, remove necrotic debris, and release noxious vasoactive 
substances trapped in the spinal cord post-injury $(24,32)$. In an experimental canine model, myelotomy in combination with dimethyl sulfoxide (DMSO) appeared to have an additive benefit on neurologic recovery compared to other experimental treatment combinations, although myelotomy alone was not evaluated (32). In another study on experimental SCI followed by myelotomy, there was immediate improvement in sensory evoked potential amplitude in $2 / 5$ dogs (33), suggesting temporary improvement in conduction, but it is unclear if this is sustained or associated with functional benefit. Myelotomy performed in normal dogs has been associated with extensive gray matter necrosis including destruction of ventral horn motor neurons in some dogs (34). However, clinical impairment from the procedure was generally mild to moderate and improved over several weeks as long as the lumbar intumescence was avoided (34). While a positive effect has been reported in $80 \%$ of pre-clinical animal studies, there are no published studies in naturally-occurring injury in dogs and very limited data available in humans (24). The lack of controlled studies is likely attributable to the invasiveness of myelotomy and perceived potential to exacerbate secondary injury and for long-term adverse sequelae.

\section{SYSTEMIC COMPOUND/MEDICATION-BASED THERAPIES}

A variety of systemic or "whole dog" interventions have been applied to treat dogs with IVDH. Administration of some type of systemic medication or chemical as a neuroprotective strategy for the treatment of acute IVDH has been reported to be recommended by up to a quarter of specialist veterinarians (35). This varied greatly by treatment type, being highest for steroid administration (34\% of boarded surgeons, $23 \%$ of boarded neurologists recommended) and $<10 \%$ for other interventions (35). Adjunctive, non-medication-based therapies typically applied post-operatively were also variably reported as part of an integrated treatment strategy. Physical rehabilitation was most common and recommended by approximately half of treating veterinarians (35).

\section{Corticosteroids}

Corticosteroids are a commonly administered adjunctive therapy for the treatment of IVDH in dogs. Methylprednisolone (MPSS) at so-called "shock doses" has received the most attention and been most extensively examined but dexamethasone has also been investigated in dogs $(17-19,32,36-43)$. MPSS has been advocated as a neuroprotective treatment for acute SCI through its mitigation of secondary injury primarily through amelioration of lipid peroxidation, other free radical, and oxidative damage and reperfusion injury (44). Although initial results of human clinical trials appeared supportive of use of high dose MPSS for treatment of SCI, subsequent re-analysis of the data cast doubt on the original treatment effect and highlighted risks of adverse effects (45-47). In dogs with IVDH, a benefit for MPSS has not been identified and complications have been reported (36, 42,
$43,48)$ and the use of MPSS remains controversial (46). The role of corticosteroids in this population is discussed in depth in the companion article "Current approaches to the management of acute thoracolumbar disc extrusion in dogs."

\section{Polyethylene Glycol}

Polyethylene glycol (PEG) a hydrophilic polymer capable of fusing cell membranes has been infrequently investigated as a treatment for acute SCI with inconsistent results. In an acute canine spinal cord transection model, immediate application of PEG at the site of injury was determined to be beneficial and to re-establish anatomic continuity (49). In a study of dogs with acute paraplegia with absent pain perception due to IVDH, intravenous PEG administration appeared safe, and associated with modestly improved neurologic status 6-8 weeks after injury and surgery compared to what might be expected in similarly affected dogs not receiving PEG (50). In a more recent clinical trial of acute paraplegic dogs with absent pain perception due to IVDH, no benefit was demonstrated for PEG compared to placebo (36).

\section{Matrix Metalloproteinases}

Matrix metalloproteinases (MMPs) are released by cells to degrade the extracellular matrix. MMPs, specifically MMP-9 and MMP-12, have been shown to be upregulated following SCI and are implicated in the deleterious secondary injury cascade. In two prospective studies, Levine et al. evaluated a broadspectrum MMP inhibitor, GM6001, in dogs treated surgically for IVDH resulting in acute $(<48 \mathrm{~h})$ non-ambulatory paraparesis or paraplegia $(51,52)$. All dogs were treated immediately before decompressive surgery with the compound, GM6001, combined with DMSO $(n=81)$, DMSO alone $(n=84)$, placebo $(n=41)$, or received no treatment $(n=20)$. Transient injection site reactions were common in the GM6001 treated dogs (which could have compromised the blinding) and a subset $(n=6)$ developed self-limiting musculoskeletal signs, but it was otherwise welltolerated. Treatment with GM6001 with DMSO resulted in improved neurologic recovery compared to placebo but was not different compared to DMSO alone. While efficacy for treatment with this MMP inhibitor was not demonstrated with regard to sensorimotor recovery, it did increased long-term bladder compliance.

\section{Dimethyl Sulfoxide}

Dimethyl sulfoxide (DMSO) is most often used as a vehicle to improve drug solubility but has been uncommonly investigated as an intervention for brain and SCI $(38,52)$. Its purported benefit in central nervous system trauma has been attributed to a reduction in edema, diuretic, anti-inflammatory and vasodilatory effects, and cellular protection from mechanical damage $(38,53)$. In several studies utilizing an experimental weight drop model, dogs were treated with DMSO (1-4.5 g/ $/ \mathrm{kg} / \mathrm{d}$ in $40 \%$ solution with $0.9 \% \mathrm{NaCl}$ ) alone or in combination with other experimental therapies and compared to control dogs $(38,53-55)$. In most, DMSO was reported to be beneficial when initially administered within $1 \mathrm{~h}$ of induced trauma although one study reported no benefit and no clear synergistic effect was observed by 
combining DMSO with dexamethasone or other experimental therapies. As outlined above, DMSO (1 g/kg) was shown to be beneficial compared to placebo in a clinical trial of dogs with IVDH (52). However, Hoerlein et al. also investigated this in acute spinal cord trauma in dogs and found it not to be useful compared to dexamethasone (56). Toxicity due to DMSO was not observed in any of the reported studies and further investigation is warranted regarding its potential therapeutic effect in this population.

\section{Other Compounds/Medications}

$\mathrm{N}$-acetylcysteine (NAC) is a precursor of glutathione with potent antioxidant as well as anti-inflammatory and neuronal protective properties that has been proposed as a treatment for acute SCI (57). In a cohort of 70 dogs undergoing surgery for acute IVDH, NAC administered IV prior to decompressive surgery showed no benefit compared to placebo with regard to neurologic outcome or rate or recovery (58). There is only anecdotal reference of veterinarians using other antioxidants such as coenzyme Q10 or vitamin E following SCI in dogs $(35,59)$. While optimizing nutritional status, weight management, and diets to reduce fecal volume in incontinent dogs are variably implemented as part of post-injury management in dogs, there is no evidence to support specific antioxidant nutraceutical supplementation or nutritional strategies to treat dogs with acute SCI.

There are other rarely reported interventions with limited, mostly experimental evidence in dogs. Analogs of the hypothalamic hormone, thyrotropin releasing hormone (TRH), have been reported to inconsistently improve outcomes after SCI in humans and experimental models (59). In a pilot study of dogs with IVDH, a benefit of a TRH analog was not identified compared to no treatment (60). Crocetin, a carotenoid that increases oxygen diffusion in plasma, was investigated in an experimental weight drop model as a means to counteract local hypoxia and subsequent ischemic necrosis following SCI. Results showed improved neurologic function in crocetin-treated dogs at 4 weeks post-injury compared to control dogs (61). Hyperosmotic agents, mannitol, urea and hypertonic dextrose, have also been evaluated with the goal of reducing swelling $(32,53,54,62)$ but did not appear to improve neurologic recovery compared with control dogs. Improvement in spinal sensory evoked potentials did occur following mannitol infusion in one study $(32,53,54,62)$. Phenytoin, an anticonvulsant, was explored as a SCI treatment based on experimental evidence that it decreases edema of neural tissues through inhibition of antidiuretic hormone and inactivation of catecholamines (40). In an experimental dog model, phenytoin resulted in improved outcome compared to untreated dogs and was at least as effective as dexamethasone, although hypotension and respiratory depression were possible adverse effects (40). Neither reserpine, an alkaloid medication used to treat high blood pressure, nor chlorpromazine, a phenothiazine with various psychiatric and other uses, were effective as treatments for experimentally induced injury in dogs $(32,39)$. There is no convincing evidence for the use of these compounds in dogs with acute SCI due to IVDH.

\section{SYSTEMIC NON-MEDICATION-BASED THERAPIES}

Various systemic, non-medication-based therapies have been advocated for the treatment of acute SCI in dogs including physical rehabilitation, hyperbaric oxygen therapy, and electroacupuncture.

\section{Physical Rehabilitation}

Physical rehabilitation in dogs recovering from surgery due to IVDH is being increasingly utilized, recommended by $58 \%$ of board-certified surgeons and neurologists surveyed (35, 63). While timing of initiation and specific protocols vary, physical rehabilitation in the neurologic patient typically consists of some combination of passive range of motion, massage, cold or warm packing, assisted balance, standing, coordination and land treadmill, or over-ground walking exercises and aquatic therapy such as underwater treadmill walking or swimming (64). It can be performed on an inpatient or out-patient basis in dogs with specific aspects tailored to patient function (e.g., underwater treadmill walking sessions are typically initiated once motor function is present). Additional specific therapies including therapeutic laser therapy, acupuncture, and neuromuscular electrical stimulation are variably included $(63,64)$.

For details on the currently available evidence regarding the role of physical rehabilitation in dogs recovering from IVDH, the reader is referred to the companion article "Current approaches to the management of acute thoracolumbar disc extrusion in dogs" in this issue. While there have been relatively few studies performed in this population and the results have been mixed, early post-operative initiation of rehabilitation has been determined to be safe with no associated adverse events or increased post-operative pain $(8,65-70)$. Inclusion of dogs of variable neurologic severity limits making direct comparisons between studies and conclusions regarding efficacy. Additionally, the role of physical rehabilitation in medically managed presumptive or confirmed IVDH has not been evaluated. Additional investigation of physical rehabilitation in dogs recovering from IVDH is warranted focusing on optimization of protocols (e.g., specific modalities, timing, and duration) and development of validated, objective outcome measures such as the Finnish neurological function testing battery for dogs (FINFUN) (71).

\section{Hyperbaric Oxygen Therapy}

Hyperbaric oxygen therapy has been uncommonly reported as a treatment for acute SCI. The proposed mechanism is to increase the tissue partial pressure of oxygen and counteract the adverse effects of spinal cord hypoxia associated with injury (72). There is limited experimental evidence in dogs suggesting a potential benefit of hyperbaric oxygen therapy compared to untreated controls but no additive effect was appreciated when combined with DMSO $(54,72)$. There are no reports in dogs with IVDH though it is used in clinical cases by some veterinarians (35). 


\section{Electroacupuncture}

Electroacupuncture has been occasionally reported as a therapy for acute SCI in dogs $(73,74)$. Its mechanism of action is unknown, but it might have analgesic and antiinflammatory effects as well as facilitating axonal repair and regrowth $(37,63)$. In an experimental canine SCI model, electroacupuncture (initiated $48 \mathrm{~h}$ post-injury and continued every other day) resulted in improved rate of recovery compared to untreated controls; the benefit appeared synergistic with concurrent MPSS (37). In one retrospective and two prospective case series of dogs with thoracolumbar IVDH of variable severity, electroacupuncture (administered 1-3 $\times /$ week for 1-6 months between studies) was reported to be more effective than decompressive surgery alone for regaining ambulation (75), and was associated with shorter time to walking and a greater proportion of dogs becoming ambulatory compared to medical management alone $(73,74)$. There was no significant difference in recovery among deep pain negative dogs managed medically with or without electroacupuncture (74). Study limitations for the prospective studies included lack of blinding or randomization, use of historical controls and small sample size within each neurologic grade $(74,75)$. There is equivocal evidence that electroacupuncture decreases the severity and duration of post-operative pain in dogs with IVDH $(74,76)$. Electroacupuncture has also been combined with stem cell transplantation in a small group of dogs chronically ( $>3$ months) deep pain negative following acute IVDH (77). This pilot study showed these interventions were feasible and safe but case numbers in each treatment group were small.

\section{ADJUNCTIVE THERAPIES IMPLEMENTED IN THE SUBACUTE-TO-CHRONIC PHASE}

Treatment strategies are also being explored for dogs with permanent impairment following acute SCI. These are typically applied in the subacute-to-chronic stage ( $>1$ month from the time of injury) and include spinal cord radiation, electrical stimulation of the spinal cord or specific nerves below the injury, nerve grafting, 4-aminopyridine, chondroitinase ABC delivery, and cell transplantation.

\section{Spinal Cord Radiation}

Spinal cord radiation has been evaluated in rodents and in an experimental model in Beagles (78). Radiation of the injured cord aims to interfere with the cell cycle to counteract the development of localized chronic inflammation, reduce glial scar formation, and facilitate axonal regrowth and healing $(78,79)$. In Beagles treated with daily radiation for 2 weeks following spinal cord hemitransection, there was reduced astrocyte and microglial activation, reduced expression of inflammatory mediators, improved long-range axonal regeneration, and improved locomotor recovery (79). This therapy has not been reported in dogs with naturally-occurring injury secondary to IVDH.

\section{Functional Electrical Stimulation}

Functional electrical stimulation has not yet been reported in dogs, but a wearable device is being developed that might be useful in dogs with incomplete recovery from acute IVDH (80). Short-term, low-intensity electrical stimulation of the spinal cord with or without stem cell transplantation has been performed in chronically paraplegic dogs (81). While electromyographic changes in pelvic limb muscles implied improvement in motor conduction, further investigation would be necessary to optimize therapy and determine if there is a clinical benefit (81). Additionally, there is experimental evidence and data in dogs with naturally-occurring injury for electrical stimulation of peripheral nerves or nerve roots to aid in restoration of urination and defecation (82-84). Electrical sacral nerve stimulation in dogs is covered in the companion article "Bladder and bowel management in dogs with spinal cord injury" in this issue.

\section{Peripheral Nerve Grafting}

Grafting of peripheral nerves from above the injury level (e.g., specific intercostal nerves) into the distal portion of experimentally transected spinal cord has also been performed in dogs with the goal of harnessing the regenerative potential of the peripheral nervous system (85-87). Nerve to nerve or nerve root grafting techniques have also been reported as therapies that aim to restore function while bypassing the spinal cord lesion directly. Toreih demonstrated the feasibility of intercostal to gluteal nerves and ilioinguinal and iliohypogastric to femoral nerves in a dog spinal cord hemisection model (88). Six months following these nerve transfer procedures, there was clinical and electrophysiological evidence of some recovery of hip, gluteal and knee function, though spontaneous improvement is well-known to occur in spinal cord hemisection models and could have resulted in the improvement observed. Vagophrenic nerve anastomosis was also shown to be anatomically feasible in dogs with the ultimate goal to provide a conduit for restoration of respiratory function after severe cervical SCI (89). Nerve anastomoses to reinstate bladder function have also been performed experimentally in dogs (90-94).

\section{Molecular Compounds Given in the Chronic Phase of SCI}

Additional compounds that have been investigated in chronically impaired dogs include 4-aminopyridine (4AP) and chondroitinase ABC. 4-aminopyridine is a potassium channel antagonist that has been shown to restore hind limb motor function in some dogs with chronic thoracolumbar SCI $(95,96)$. This effect is mediated through enhancement of central conduction via anatomically intact axons traversing the site of injury as well as direct synaptic effects (97-99). Response following oral administration is highly variable between individual dogs with a minority regaining independent ambulation $(96,98)$. Lack of predictable response and narrow therapeutic window have limited widespread use of this medication among chronically paralyzed dogs.

Chondroitinase $\mathrm{ABC}$ is an enzyme that degrades chondroitin sulfate proteoglycans which are key components of the glial scar and inhibitors of axonal regeneration following SCI (100). This 
has led to active research regarding the use and optimization of chondroitinase ABC to treat SCI (100). A prospective clinical trial of intraspinal injection of a long acting chondroitinase $\mathrm{ABC}$ in dogs with naturally occurring severe SCI reported functional improvements compared to sham controls including improved thoracic to pelvic limb coordination and three dogs with restoration of ambulation (101). In an experimental canine model, the combination of chondroitinase ABC with mesenchymal stem cell transplantation was also reported to improve neurologic deficits and enhance neural regeneration (102). However, this study had a small number of dogs, lacked blinding of the observations and the locomotor outcome measure might not reflect voluntary movements (102).

\section{CELL TRANSPLANTATION STRATEGIES}

Transplantation of cells into the spinal cord has been investigated in dogs either after creating an experimental spinal cord lesion or after naturally-occurring SCI. This involves predominantly stem cell therapies such as mesenchymal stem cells of various origin, neural stem cells, or bone marrow-derived mononuclear cells but other fully differentiated cells have been used such as olfactory glial cells, olfactory mucosal cells, Schwann cells, or macrophages. Most commonly, the cell transplants are administered via intraparenchymal or intrathecal injection but intravenous delivery has also been reported.

\section{Cell Transplantation for Spinal Cord Repair in Experimental Dogs}

Placement and inflation of a ventral epidural balloon has been used to produce experimental compression and contusion of the dog spinal cord $(103,104)$. Developed in the seventies by investigators such as Kobrine and Griffiths, this technique has the advantage of producing a closed injury, without the need to open the spinal canal via a laminectomy, and causes more vascular injury (ischemia) than weight-drop models $(105,106)$, although lesions lack reproducibility. Using this model, the effect of canine and human umbilical cord blood-derived mesenchymal stem cells, adipose-derived stem cells (some genetically modified), or bone marrow-derived mesenchymal stem cells (107-117) has been tested. These cell transplants were reported to improve locomotor function, but experimental groups consisted of small numbers (between two and five), observers were not blinded and tail support was used when testing locomotion [which is likely to trigger "involuntary" stepping pelvic movements that are independent from brain connections $(118,119)]$. However, histopathological data demonstrated survival of some transplanted cells, albeit with limited integration within the host spinal cord, suggesting that the locomotor improvement could have been due to secretion of trophic or growth factors into the region of injury (107).

A canine hemisection model in which a gel seeded with human neural stem cells was placed immediately into the hemisected spinal cord gap $(120,121)$ showed better locomotor recovery and more ascending sensory axons in dogs receiving cells alone in one study (121) and no effect in another study (122).
A canine transection model has been reported from groups in China recently, testing the effect of collagen-based biomaterial loaded with human umbilical cord-derived mesenchymal stem cells (123), human placenta-derived mesenchymal stem cells (124), or bone marrow-derived mesenchymal stem cells differentiated into neuron-like cells (125). Recipients of cells had improved locomotor scores compared to controls but remained non-ambulatory and the studies were not blinded. Interestingly, cells survived up to 6 months.

A group from Egypt described a compression/contusion model using a "clip" placed on the spinal cord at the L4 spinal cord segment; neural-induced bone marrow derived stem cells were then injected intrathecally by lumbar puncture 2 weeks after the injury by a blinded investigator (126). The injury initially caused paralysis and loss of pain perception in all dogs, but those receiving the cell transplant had much greater recovery of motor function compared to controls. Further, cells could be found surviving in the lesion at 16 weeks after injection. This work represents a lesion and intervention paradigm that are much closer to clinical injuries than other experimental models.

In summary, there is a growing number of transplantation experiments originating primarily from Korea and China which have generally low power and follow the same experimental pattern with varying cell types. One group in Korea translated their experiment to the clinic by transplanting adipose-derived stem cells (112) to 9 companion dogs with paraplegia and no deep pain (127) but trial design lacked clear inclusion criteria and blinding. Therefore, the utility of these treatments for clinical populations remains to be validated in randomized, blinded studies. A cautious approach has been followed by other laboratories, for example, McMahill et al. at the University of California Davis Medical Center, where they have transplanted canine epidermal neural crest stem into normal canine spinal cord (128) and focused on developing strong outcome measures using cell tracking with magnetic resonance imaging and detailed gait analysis. They showed survival of cells at 3 weeks post-transplantation and are likely now envisaging clinical trials in companion dogs with naturally-occurring lesions. There is also uncertainty as to which cell type, stem cells or other differentiated cells, should be prioritized. For example, two other groups have postulated that transplantation of Schwann cells purified from peripheral nerves or nerve roots could be a repair strategy worth pursuing following SCI in dogs $(129,130)$. Additionally, transplantation strategies can be leveraged to investigate application of biologics (e.g., chondroitinase $\mathrm{ABC}$ ) to the lesion site as a means to promote cell survival, regrowth, or mitigate inhibition of axonal regeneration.

\section{Cell Transplantation Within the Spinal Cord in Dogs With Naturally-Occurring Injury}

One of the best known cell type studied in dogs is olfactory ensheathing cells, which are not stem cells but fully differentiated cells located within the olfactory mucosa and olfactory bulb, forming an interface between the peripheral and central nervous 
systems (131-133). Olfactory ensheathing cells have been reliably cultured for a long time in neuroscience (134), including in dogs (135-138) and have been used in clinical applications $(139,140)$. They are recognized for their regenerative properties when transplanted within a lesion of the central nervous system. In particular, they are able to form channels guiding axonal regrowth (141) and to remyelinate axons (142). In a randomized controlled trial in dogs with irreversible chronic SCI, autologous olfactory ensheathing cells obtained from the nasal mucosa have been shown to improve thoracic to pelvic limb coordination (143). However, these cells were not able to restore brain-controlled functions such as urinary continence, prompting research into strategies to improve their efficacy. More recently, olfactory ensheathing cells have been engineering to express the chondroitinase $\mathrm{ABC}$ enzyme that degrades the glial scar (144), though these have not yet been transplanted into dogs.

In the last decade, there has been an increasing number of publications from Japan, Brazil, Turkey, and India testing different cell transplants in dogs with naturally-occurring injury. First in Japan, two groups reported that autologous bone marrow stromal or mononuclear cell transplants were safe in 7 (145) and 1 (146) dogs with chronic paraplegia and absent deep pain.

Since 2014, institutions in Brazil have reported seven trials testing safety or efficacy of various cell transplants (within the spinal cord or in the sub-arachnoid or epidural space) in small series of companion dogs, sometimes with concomitant spinal cord decompression, or in association with other alternative therapies such as electroacupuncture (77) or lowintensity electrical stimulation (81). The cells tested have been either autologous bone marrow mesenchymal stem cells (147), allogenic fetal bone marrow stem cells (148), allogenic canine adipose tissue-derived mesenchymal stem cells $(81,149,150)$ or immature dental pulp stem cells $(77,151)$.

The follow-up duration in these studies was usually of several months. Taken together, the results suggest an improvement of locomotor function, based on an increase in locomotor scores. However, these cases rarely achieved scores suggesting unassisted ambulation and for those that did walk again, they remained deep pain negative suggesting that the locomotion could have been independent of the therapeutic intervention (i.e., "spinal walking"). Interestingly, in some dogs, there was reported recovery of deep pain $(147,148)$ but no concomitant recovery of locomotion. These findings could indicate that the transplanted cells have a beneficial effect. However, data are limited and these studies also illustrate the heterogeneity of clinical lesions and the need to increase case numbers to better assess the efficacy of cell transplant techniques.

In Turkey, Besalti et al. transplanted intramedullary neurogenically-induced bone marrow-derived mesenchymal stem cells 42 days after the initial injury (152). They conducted detailed follow-up over 12 months and found that 2 out of 13 dogs recovered somatosensory evoked potentials and magnetic motor evoked potentials, while some other dogs had improved gait scores (6/13) and regained deep pain sensation. Bhat et al. in India also reported a trial in 44 dogs testing bone marrow mesenchymal stem cells without decompressive surgery
(153). The authors claimed improved deep pain sensation and locomotion, but the change compared to the control group remained clinically small.

Altogether, the results of various cell transplantation studies in dogs are encouraging, although most studies remain of low power and preliminary. They have proven safety, but the recovery is always limited to a proportion of studied dogs and recovery of one function at a time, either locomotion, continence, or pain perception. This perhaps suggests that other factors than the actual treatment led to the change in function and highlights the severity of lesions and difficulties in repairing them. A consensus on which intervention holds the greatest promise would be useful to then apply in large multicenter trials in dogs, where evaluation of efficacy could be investigated with greater power.

\section{CONCLUSIONS}

In conclusion, we have outlined a variety of therapeutic strategies that have been applied to dogs with SCI in both the acute as well as subacute-to-chronic settings. These range from those applied to the spinal cord directly to systemic treatments and with variable goals from repair to compensation. While some techniques are more promising than others, they all serve to highlight the challenges in treating severe SCI and in developing successful treatment options for a heterogeneous clinical population. Moving forward, multimodal approaches to therapy building on conventional treatment options will likely be most successful.

\section{AUTHOR CONTRIBUTIONS}

ML, NG, and NJ participated in manuscript conception, preparation, and editing with the first two (ML and $\mathrm{NG)}$ contributing equally. The additional members of the CANSORT-SCI consortium contributed to manuscript conception, editing, and review.

\section{CANSORT SCI AFFILIATIONS}

- Sarah A. Moore, DVM, DACVIM-Neurology, Associate Professor, Neurology and Neurosurgery, Department of Veterinary Clinical Sciences, The Ohio State University College of Veterinary Medicine, Columbus, OH, United States

- Natasha J. Olby, Vet MB, Ph.D., DACVIM-Neurology, Professor of Neurology/Neurosurgery, Dr. Kady M. Gjessing and Rhanna M. Davidson Distinguished Chair of Gerontology, Department of Clinical Sciences, North Carolina State University College of Veterinary Medicine, Raleigh, NC, United States

- Jonathan M. Levine, DVM, DACVIM-Neurology, Professor, Helen McWhorter Chair, and Head, Department of Small Animal Clinical Sciences, College of Veterinary Medicine and Biomedical Sciences, Texas A\&M University, College Station, TX, United States

- Melissa J. Lewis, VMD, Ph.D., DAVCIM-Neurology, Assistant Professor of Neurology, Department of Veterinary Clinical 
Sciences, Purdue University College of Veterinary Medicine, West Lafayette, IN, United States

- Nick D. Jeffery, Professor Neurology \& Neurosurgery, Maureen E. Mullins Professor in Small Animal Clinical Sciences, College of veterinary Medicine, Texas A\&M University, College Station, TX, United States

- Ronaldo Casimiro da Costa, DMV, MSc, Ph.D., Dipl. ACVIMNeurology, Professor and Service Head, Neurology and Neurosurgery, Department of Veterinary Clinical Sciences, College of Veterinary Medicine, The Ohio State University, Columbus, $\mathrm{OH}$, United States

- Yvette S. Nout-Lomas, DVM, Ph.D., Department of Clinical Sciences, Colorado State University, Fort Collins, CO, United States

- Joe Fenn, BVet Med, MVetMed, FHEA, MRCVS, Department of Clinical Science and Services, Royal Veterinary College, Hawkshead Lane, Hatfield, Hertfordshire, United Kingdom

- Dr. Nicolas Granger, DVM, Ph.D., DECVN, FHEA, MRCVS, The Royal Veterinary College, University of London,

\section{REFERENCES}

1. Burns TC, Verfaillie CM. From mice to mind: strategies and progress in translating neuroregeneration. Eur J Pharmacol. (2015) 759:90-100. doi: 10.1016/j.ejphar.2015.03.041

2. Jeffery ND, Smith PM, Lakatos A, Ibanez C, Ito D, Franklin RJM. Clinical canine spinal cord injury provides an opportunity to examine the issues in translating laboratory techniques into practical therapy. Spinal Cord. (2006) 44:584-93. doi: 10.1038/sj.sc.3101912

3. Bart van der Worp H, Howells DW, Sena ES, Porritt MJ, Rewell S, O'Collins $\mathrm{V}$, et al. Can animal models of disease reliably inform human studies? PLoS Med. (2010) 7:e1000245. doi: 10.1371/journal.pmed.1000245

4. Hackam DG, Redelmeier DA. Translation of research evidence from animals to humans. J Am Med Assoc. (2006) 296:1731-2. doi: $10.1001 /$ jama.296.14.1731

5. Hamblin MR. Mechanisms and applications of the anti-inflammatory effects of photobiomodulation. AIMS Biophys. (2017) 4:337-61. doi: 10.3934/biophy.2017.3.337

6. Hashmi JT, Huang YY, Osmani BZ, Sharma SK, Naeser MA, Hamblin MR. Role of low-level laser therapy in neurorehabilitation. PMR. (2010) 2:S292-305. doi: 10.1016/j.pmrj.2010.10.013

7. Draper WE, Schubert TA, Clemmons RM, Miles SA. Low-level laser therapy reduces time to ambulation in dogs after hemilaminectomy: a preliminary study. J Small Anim Pract. (2012) 53:465-9. doi: 10.1111/j.1748-5827.2012.01242.x

8. Bennaim M, Porato M, Jarleton A, Hamon M, Carroll JD, Gommeren $\mathrm{K}$, et al. Preliminary evaluation of the effects of photobiomodulation therapy and physical rehabilitation on early postoperative recovery of dogs undergoing hemilaminectomy for treatment of thoracolumbar intervertebral disk disease. Am J Vet Res. (2017) 78:195-206. doi: 10.2460/ajvr. 78.2.195

9. Crowe MJ, Sun ZP, Battocletti JH, Macias MY, Pintar FA, Maiman DJ. Exposure to pulsed magnetic fields enhances motor recovery in cats after spinal cord injury. Spine. (2003) 28:2660-6. doi: 10.1097/01.BRS.0000099385.46102.0D

10. Hattapoglu E, Batmaz I, Dilek B, Karakoç M, Em S, Çevik R. Efficiency of pulsed electromagnetic fields on pain, disability, anxiety, depression, and quality of life in patients with cervical disc herniation: a randomized controlled study. Turkish J Med Sci. (2019) 49:1095-101. doi: 10.3906/sag-1901-65

11. Lisi AJ, Scheinowitz M, Saporito R, Onorato A. A pulsed electromagnetic field therapy device for non-specific low back pain:
Hawkshead Lane, Hatfield, United Kingdom and CVS Referrals, Bristol Veterinary Specialists at Highcroft, Bristol, United Kingdom

- Dr. Ingo Spitzbarth, Ph.D., Dipl. ECVP, Faculty of Veterinary Medicine, Institute of Veterinary Pathology, Leipzig University, Leipzig, Germany

- Veronika M. Stein, Prof. Dr. Ph.D. DECVN, Division of Clinical Neurology, Department for Clinical Veterinary Medicine, Vetsuisse Faculty, University of Bern, Bern, Switzerland

- Prof. Dr. Andrea Tipold, Dipl. ECVN, Department Small Animal Medicine and Surgery, University of Veterinary Medicine Hannover, Hannover, Germany/Europe

- Ji-Hey Lim, DVM, Ph.D., Neurology and Neurosurgery, Department of Veterinary Medicine and Surgery, University of Missouri, Columbia, MO, United States

- Holger Volk, Ph.D., PGCAP, Dipl. ECVN, Department of Small Animal Medicine and Surgery, University of Veterinary Medicine Hannover, Hannover, Germany/Europe a pilot randomized controlled trial. Pain Ther. (2019) 8:1330140. doi: 10.1007/s40122-019-0119-z

12. Sorrell RG, Muhlenfeld J, Moffett J, Stevens G, Kesten S. Evaluation of pulsed electromagnetic field therapy for the treatment of chronic postoperative pain following lumbar surgery: a pilot, double-blind, randomized, sham-controlled clinical trial. J Pain Res. (2018) 11:1209-22. doi: 10.2147/JPR.S164303

13. Alzayed KA, Alsaadi SM. Efficacy of pulsed low-frequency magnetic field therapy on patients with chronic low back pain: a randomized double-blind placebo-controlled trial. Asian Spine J. (2020) 14:33-42. doi: 10.31616/asj.2019.0043

14. Zidan N, Fenn J, Griffith E, Early PJ, Mariani CL, Muñana KR, et al. The effect of electromagnetic fields on post-operative pain and locomotor recovery in dogs with acute, severe thoracolumbar intervertebral disc extrusion: a randomized placebo-controlled, prospective clinical trial. J Neurotrauma. (2018) 35:1-11. doi: 10.1089/neu.2017.5485

15. Borgens RB, Toombs JP, Blight AR, McGinnis ME, Bauer MS, Widmer WR, et al. Effects of applied electric fields on clinical cases of complete paraplegia in dogs. Restor Neurol Neurosci. (1993) 5:305-22. doi: 10.3233/RNN-1993-55601

16. Borgens RB, Toombs JP, Breur G, Widmer WR, Waters D, Harbath AM, et al. An imposed oscillating electrical field improves the recovery of function in neurologically complete paraplegic dogs. J Neurotrauma. (1999) 16:639-57. doi: 10.1089/neu.1999.16.639

17. Ducker TB, Hamit HF. Experimental treatments of acute spinal cord injury. J Neurosurg. (1969) 30:693-7. doi: 10.3171/jns.1969.30.6.0693

18. Hansebout RR, Kuchner EF, Romero Sierra C. Effects of local hypothermia and of steroids upon recovery from experimental spinal cord compression injury. Surg Neurol. (1975) 4:531-6.

19. Kuchner EF, Hansebout RR. Combined steroid and hypothermia treatment of experimental spinal cord injury. Surg Neurol. (1976) 6:371-6.

20. Wells JD, Hansebout RR. Local hypothermia in experimental spinal cord trauma. Surg Neurol. (1978) 10:200-4.

21. Fenn J, Laber E, Williams K, Rousse CA, Early PJ, Mariani CL, et al. associations between anesthetic variables and functional outcome in dogs with thoracolumbar intervertebral disk extrusion undergoing decompressive hemilaminectomy. J Vet Intern Med. (2017) 31:814-24. doi: 10.1111 /jvim. 14677

22. Martirosyan NL, Patel AA, Carotenuto A, Kalani MYS, Bohl MA, Preul MC, et al. The role of therapeutic hypothermia in the management of acute spinal cord injury. Clin Neurol Neurosurg. (2017) 154:79-88. doi: 10.1016/j.clineuro.2017.01.002 
23. Alkabie S, Boileau AJ. The role of therapeutic hypothermia after traumatic spinal cord injury - a systematic review. World Neurosurg. (2016) 86:432-49. doi: 10.1016/j.wneu.2015.09.079

24. Telemacque D, Zhu FZ, Ren ZW, Chen KF, Drepaul D, Yao S, et al. Effects of durotomy vs. myelotomy in the repair of spinal cord injury. Neural Regen Res. (2020) 15:1814-20. doi: 10.4103/1673-5374.280304

25. Allen AR. Surgery of experimental lesion of spinal cord equivalent to crush injury of fracture dislocation of spinal column: a preliminary report. J Am Med Assoc. (1911) LVII:878-80. doi: 10.1001/jama.1911.042600901 00008

26. Blaser A, Lang J, Henke D, Doherr MG, Adami C, Forterre F. Influence of durotomy on laser-doppler measurement of spinal cord blood flow in chondrodystrophic dogs with thoracolumbar disk extrusion. Vet Surg. (2012) 41:221-7. doi: 10.1111/j.1532-950X.2011.00909.x

27. Parker AJ, Smith CW. Functional recovery from spinal cord trauma following incision of spinal meninges in dogs. Res Vet Sci. (1974) 16:276-9. doi: $10.1016 /$ S0034-5288(18)33725-1

28. Parker AJ, Smith CW. Functional recovery from spinal cord trauma following delayed incision of spinal meninges in dogs. Res Vet Sci. (1975) 18:110-2. doi: 10.1016/S0034-5288(18)33641-5

29. Loughin CA, Dewey CW, Ringwood PB, Pettigrew RW, Kent M, Budsberg SC. Effect of durotomy on functional outcome of dogs with type I thoracolumbar disc extrusion and absent deep pain perception. Vet Comp Orthop Traumatol. (2005) 18:141-6. doi: 10.1055/s-0038-1632953

30. Takahashi F, Honnami A, Toki M, Dosaka A, Fujita Y, Hara Y, et al. Effect of durotomy in dogs with thoracolumbar disc herniation and without deep pain perception in the hind limbs. Vet Surg. (2020) 49:860-9. doi: 10.1111/vsu.13409

31. Jeffery ND, Mankin JM, Ito D, Boudreau CE, Kerwin SC, Levine JM, et al. Extended durotomy to treat severe spinal cord injury after acute thoracolumbar disc herniation in dogs. Vet Surg. (2020) 49:884-93. doi: $10.1111 /$ vsu. 13423

32. Rucker NC, Lumb W V., Scott RJ. Combined pharmacologic and surgical treatments for acute spinal cord trauma. Am J Vet Res. (1981) 42:1138-42.

33. Isu T, Iwasaki $\mathrm{Y}$, Akino $\mathrm{M}$, Abe $\mathrm{H}$. Effect of mannitol administration and myelotomy on acute experimental spinal cord injury: investigation by spinal cord evoked potential. Neurol Surg. (1990) 18:267-72.

34. Teague HD, Brasmer TH. Midline myelotomy of the clinically normal canine spinal cord. Am J Vet Res. (1978) 39:1584-90.

35. Moore SA, Early PJ, Hettlich BF. Practice patterns in the management of acute intervertebral disc herniation in dogs. J Small Anim Pract. (2016) 57:409-15. doi: 10.1111/jsap. 12496

36. Olby NJ, Muguet-Chanoit AC, Lim JH, Davidian M, Mariani CL, Freeman AC, et al. A placebo-controlled, prospective, randomized clinical trial of polyethylene glycol and methylprednisolone sodium succinate in dogs with intervertebral disk herniation. J Vet Intern Med. (2016) 30:206-14. doi: 10.1111 /jvim. 13657

37. Yang JW, Jeong SM, Seo KM, Nam TC. Effects of corticosteroid and electroacupuncture on experimental spinal cord injury in dogs. J Vet Sci. (2003) 4:97-101. doi: 10.4142/jvs.2003.4.1.97

38. de la Torre JC, Johnson CM, Goode DJ, Mullan S. Pharmacologic treatment and evaluation of permanent experimental spinal cord trauma. Neurology. (1975) 25:508-14. doi: 10.1212/WNL.25.6.508

39. Parker AJ, Smith CW. Functional recovery from spinal cord trauma following dexamethazone and chlorpromazine therapy in dogs. Res Vet Sci. (1976) 21:246-7. doi: 10.1016/S0034-5288(18)33383-6

40. Gerber AM, Olson WL, Harris JH. Effect of phenytoin on functional recovery after experimental spinal cord injury in dogs. Neurosurgery. (1980) 7:472-6. doi: 10.1227/00006123-198011000-00009

41. Coates JR, Sorjonen DC, Simpson ST, Cox NR, Wright JC, Hudson JA, et al. Clinicopathologic EFFECTS of a 21-Aminosteroid compound (U74389G) and high-dose methylprednisolone on spinal cord function after simulated spinal cord trauma. Vet Surg. (1995) 24:128-39. doi: 10.1111/j.1532-950X.1995.tb01307.x

42. Laitinen OM, Puerto DA. Surgical decompression in dogs with thoracolumbar intervertebral disc disease and loss of deep pain perception: a retrospective study of 46 cases. Acta Vet Scand. (2005) 46:79-85. doi: 10.1186/1751-0147-46-79
43. Levine JM, Levine GJ, Boozer L, Schatzberg SJ, Platt SR, Kent M, et al. Adverse effects and outcome associated with dexamethasone administration in dogs with acute thoracolumbar intervertebral disk herniation: 161 cases (2000-2006). J Am Vet Med Assoc. (2008) 232:411-7. doi: $10.2460 /$ javma.232.3.411

44. Hall ED. The neuroprotective pharmacology of methylprednisolone. J Neurosurg. (1992) 76:13-22. doi: 10.3171/jns.1992.76.1.0013

45. Evaniew N, Belley-Côté EP, Fallah N, Noonan VK, Rivers CS, Dvorak MF. Methylprednisolone for the treatment of patients with acute spinal cord injuries: a systematic review and meta-analysis. J Neurotrauma. (2016) 33:468-81. doi: 10.1089/neu.2015.4192

46. Fehlings MG, Wilson JR, Harrop JS, Kwon BK, Tetreault LA, Arnold PM, et al. Efficacy and safety of methylprednisolone sodium succinate in acute spinal cord injury: a systematic review. Glob Spine J. (2017) 7:116S-37S. doi: $10.1177 / 2192568217706366$

47. Khan MF, Burks SS, Al-Khayat H, Levi AD. The effect of steroids on the incidence of gastrointestinal hemorrhage after spinal cord injury: a casecontrolled study. Spinal Cord. (2014) 52:58-60. doi: 10.1038/sc.2013.122

48. Boag AK, Otto CM, Drobatz KJ. Complications of methylprednisolone sodium succinate therapy in dachshunds with surgically treated intervertebral disc disease. J Vet Emerg Crit Care. (2001) 11:105-10. doi: 10.1111/j.1476-4431.2001.tb00076.x

49. Ren S, Liu Z, Kim CY, Fu K, Wu Q, Hou L, et al. Reconstruction of the spinal cord of spinal transected dogs with polyethylene glycol. Surg Neurol Int. (2019) 26:59. doi: 10.25259/SNI-73-2019

50. Laverty PH, Leskovar A, Breur GJ, Coates JR, Bergman RL, Widmer WR, et al. A preliminary study of intravenous surfactants in paraplegic dogs: polymer therapy in canine clinical SCI. J Neurotrauma. (2004) 21:1767-77. doi: 10.1089/neu.2004.21.1767

51. Levine JM, Cohen ND, Fandel TM, Levine GJ, Mankin J, Griffin JF, et al. early blockade of matrix metalloproteinases in spinal-cord-injured dogs results in a long-term increase in bladder compliance. J Neurotrauma. (2017) 34:2656-67. doi: 10.1089/neu.2017.5001

52. Levine JM, Cohen ND, Heller M, Fajt VR, Levine GJ, Kerwin SC, et al. Efficacy of a metalloproteinase inhibitor in spinal cord injured dogs. PLoS ONE. (2014) 9:e96408. doi: 10.1371/journal.pone.0096408

53. Kajihara K, Kawanaga H, De la Torre JC, Mullan S. Dimethyl sulfoxide in the treatment of experimental acute spinal cord injury. Surg Neurol. (1973) 13:273-6.

54. de la Torre JC, Kawanaga HM, Johnson CM, Goode DJ, Kajihara K, Mullan S. Dimethyl sulfoxide in central nervous system trauma. Ann N Y Acad Sci. (1975) 243:362-89. doi: 10.1111/j.1749-6632.1975.tb25377.x

55. Parker AJ, Smith CW. Lack of functional recovery from spinal cord trauma following dimethylsulphoxide and epsilon amino caproic acid therapy in dogs. Res Vet Sci. (1979) 27:253-5. doi: 10.1016/S0034-5288(18)32844-3

56. Hoerlein BF, Redding RW, Hoff EJ, McGuire JA. Evaluation of dexamethasone, DMSO, mannitol, and solcoseryl in acute spinal cord trauma. J Am Anim Hosp Assoc. (1983) 19:216-25.

57. Zafarullah M, Li WQ, Sylvester J, Ahmad M. Molecular mechanisms of N-acetylcysteine actions. Cell Mol Life Sci. (2003) 60:6-20. doi: 10.1007/s000180300001

58. Baltzer WI, McMichael MA, Hosgood GL, Kerwin SC, Levine JM, Steiner $\mathrm{JM}$, et al. Randomized, blinded, placebo-controlled clinical trial of $\mathrm{n}$ acetylcysteine in dogs with spinal cord trauma from acute intervertebral disc disease. Spine. (2008) 33:1397-402. doi: 10.1097/BRS.0b013e3181753c37

59. Park EH, White GA, Tieber LM. Mechanisms of injury and emergency care of acute spinal cord injury in dogs and cats. J Vet Emerg Crit Care. (2012) 22:160-78. doi: 10.1111/j.1476-4431.2012.00723.x

60. Olby NJ, Burr J, Platt SR, Papich M, Muñana KR, Faden AI. Phase I clinical trial of a thyrotropin-releasing hormone derivative in acute intervertebral disc herniation. In: Proceedings of the 21st Annual ACVIM Forum. Charlotte, NC (2008). p. 402.

61. Gainer JV. Use of crocetin in experimental spinal cord injury. J Neurosurg. (1977) 46:358-60. doi: 10.3171/jns.1977.46.3.0358

62. Isu T. Spinal cord evoked potential in experimental spinal cord injury-the changes in spinal cord evoked potential following impact injury, and effect of mannitol administration on acute experimental spinal cord injury. Hokkaido Igaku Zasshi. (1990) 65:142-51. 
63. Frank LR, Roynard PFP. veterinary neurologic rehabilitation: the rationale for a comprehensive approach. Top Companion Anim Med. (2018) 33:49-57. doi: 10.1053/j.tcam.2018.04.002

64. Thomas WB, Olby NJ, Sharon L. Neurologic conditions physical rehabilitation of the neurologic patient. In Millis DL, Levine D, Taylor R. editors. Canine Rehabilitation Physical Therapy. Philadelphia, PA: WB Saunders (1978). p. 609-27. doi: 10.1016/B978-1-4377-0309-2.00034-X

65. Gallucci A, Dragone L, Menchetti M, Gagliardo T, Pietra M, Cardinali M, et al. Acquisition of involuntary spinal locomotion (spinal walking) in dogs with irreversible thoracolumbar spinal cord lesion: 81 dogs. J Vet Intern Med. (2017) 31:492-7. doi: 10.1111/jvim.14651

66. Gordon-Evans WJ, Johnson AL, Knap KE, Griffon DJ. The effect of body condition on postoperative recovery of dachshunds with intervertebral disc disease treated with postoperative physical rehabilitation. Vet Surg. (2019) 48:159-63. doi: 10.1111/vsu.13142

67. Hodgson MM, Bevan JM, Evans RB, Johnson TI. Influence of in-house rehabilitation on the postoperative outcome of dogs with intervertebral disk herniation. Vet Surg. (2017) 46:566-73. doi: 10.1111/vsu.12635

68. Jeong IS, Piao Z, Rahman MM, Kim S, Kim NS. Canine thoracolumbar intervertebral disk herniation and rehabilitation therapy after surgical decompression: a retrospective study. J Adv Vet Anim Res. (2019) 6:394-402. doi: 10.5455/javar.2019.f359

69. Zidan N, Sims C, Fenn J, Williams K, Griffith E, Early PJ, et al. A randomized, blinded, prospective clinical trial of postoperative rehabilitation in dogs after surgical decompression of acute thoracolumbar intervertebral disc herniation. J Vet Intern Med. (2018) 32:1133-44. doi: 10.1111/jvim.15086

70. Laura LH, Peter DS. Recovery times for dogs undergoing thoracolumbar hemilaminectomy with fenestration and physical rehabilitation: a review of 113 cases. J Vet Med Anim Heal. (2015) 7:278-89. doi: 10.5897/JVMAH2015.0398

71. Boström AF, Hyytiäinen HK, Koho P, Cizinauskas S, Hielm-Björkman AK. Development of the finnish neurological function testing battery for dogs and its intra- and inter-rater reliability. Acta Vet Scand. (2018) 60:56. doi: 10.1186/s13028-018-0408-2

72. Kelly DL, Lassiter KR, Vongsvivut A, Smith JM. Effects of hyperbaric oxygenation and tissue oxygen studies in experimental paraplegia. J Neurosurg. (1972) 36:425-9. doi: 10.3171/jns.1972.36.4.0425

73. Hayashi AM, Matera JM, Pinto ACBDCF. Evaluation of electroacupuncture treatment for thoracolumbar intervertebral disk disease in dogs. J Am Vet Med Assoc. (2007) 231:913-8. doi: 10.2460/javma.231.6.913

74. Han HJ, Yoon HY, Kim JY, Jang HY, Lee B, Choi SH, et al. Clinical effect of additional electroacupuncture on thoracolumbar intervertebral disc herniation in 80 paraplegic dogs. Am J Chin Med. (2010) 38:1015-25. doi: 10.1142/S0192415X10008433

75. Joaquim JGF, Luna SPL, Brondani JT, Torelli SR, Rahal SC, De Freitas FP. Comparison of decompressive surgery, electroacupuncture, and decompressive surgery followed by electroacupuncture for the treatment of dogs with intervertebral disk disease with long-standing severe neurologic deficits. J Am Vet Med Assoc. (2010) 236:1225-9. doi: 10.2460/javma.236.11.1225

76. Laim A, Jaggy A, Forterre F, Doherr MG, Aeschbacher G, Glardon O. Effects of adjunct electroacupuncture on severity of postoperative pain in dogs undergoing hemilaminectomy because of acute thoracolumbar intervertebral disk disease. J Am Vet Med Assoc. (2009) 234:1141-6. doi: 10.2460/javma.234.9.1141

77. Prado C, Fratini P, de Sá Schiavo Matias G, Bocabello RZ, Monteiro J, dos Santos CJ, et al. Combination of stem cells from deciduous teeth and electroacupuncture for therapy in dogs with chronic spinal cord injury: a pilot study. Res Vet Sci. (2019) 123:247-51. doi: 10.1016/j.rvsc.2019.01.011

78. Kalderon N. Cell elimination as a strategy for repair in acute spinal cord injury. Curr Pharm Des. (2005) 11:1237-45. doi: 10.2174/1381612053507477

79. Zhang Q, Xiong Y, Zhu B, Zhu B, Tian D, Wang W. Low-dose fractionated irradiation promotes axonal regeneration beyond reactive gliosis and facilitates locomotor function recovery after spinal cord injury in beagle dogs. Eur J Neurosci. (2017) 46:2507-18. doi: 10.1111/ejn.13714

80. Taghavi N, Luecke GR, Jeffery ND. A wearable body controlling device for application of functional electrical stimulation. Sensors. (2018) 18:1251. doi: $10.3390 / \mathrm{s} 18041251$
81. Krueger E, Magri LMS, Botelho AS, Bach FS, Rebellato CLK, Fracaro $\mathrm{L}$, et al. Effects of low-intensity electrical stimulation and adipose derived stem cells transplantation on the time-domain analysis-based electromyographic signals in dogs with SCI. Neurosci Lett. (2019) 696:38-45. doi: 10.1016/j.neulet.2018.12.004

82. Chang SM, Yu GR, Diao YM, Zhang MJ, Wang SB, Hou CL. Sacral anterior root stimulated defecation in spinal cord injuries: an experimental study in canine model. World J Gastroenterol. (2005) 11:17158. doi: 10.3748/wjg.v11.i11.1715

83. Walter JS, Wheeler JS, Robinson CJ, Wurster RD. Surface stimulation techniques for bladder management in the spinal dog. J Urol. (1989) 141:1615. doi: 10.1016/S0022-5347(17)40632-X

84. Granger N, Chew D, Fairhurst P, Fawcett JW, Lacour SP, Craggs M, et al. Use of an implanted sacral nerve stimulator to restore urine voiding in chronically paraplegic dogs. J Vet Intern Med. (2013) 27:99-105. doi: 10.1111 /jvim. 12011

85. Turbes CC. Intercostal nerve nerve neurouma (PNS) implantation in spinal cord transection - Enhancement of locomotor recovery. Biomed Sci Instrum. (1999) 35:297-302.

86. Cseuz KA, Speakman TJ. Regenerative potential of peripheral nerve implants in the transected spinal cord of dogs. Surg Forum. (1962) 13:417-8.

87. Turbes CC. Intercostal nerve neurouma (PNS) implantation in spinal cord bridging spinal cord transection a functional internuncal pathway system result in recovery from paraplegia. Biomed Sci Instrum. (2001) 37:137-42.

88. Toreih AA, Sallam AA, Ibrahim CM, Maaty AI, Hassan MM. Intercostal, ilioinguinal, and iliohypogastric nerve transfers for lower limb reinnervation after spinal cord injury: An anatomical feasibility and experimental study. J Neurosurg Spine. (2018) 30:268-78. doi: 10.3171/2018.8.SPINE181

89. Wilson AS, Krcek JP. Restoration of function in the paralyzed diaphragm. Exp Neurol. (1975) 47:490-502. doi: 10.1016/0014-4886(75)90081-3

90. Tang J, Ma J, Yang L, Huang X, Ge Y, Sui T, et al. The feasibility study of extradural nerve anastomosis technique for canine bladder reinnervation after spinal cord injury. J Spinal Cord Med. (2016) 39:679-85. doi: 10.1080/10790268.2016.1209889

91. Lin $\mathrm{H}$, Hou C, Chen $\mathrm{A}, \mathrm{Xu} \mathrm{Z}$. Reinnervation of atonic bladder after conus medullaris injury using a modified nerve crossover technique in canines. World Neurosurg. (2010) 73:582-6. doi: 10.1016/j.wneu.2010. 02.020

92. Lin $\mathrm{H}$, Hou $\mathrm{C}$, Chen $\mathrm{A}, \mathrm{Xu} \mathrm{Z}$. Innervation of reconstructed bladder above the level of spinal cord injury for inducing micturition by contractions of the abdomen-to-bladder reflex arc. Neurosurgery. (2010) 66:948-52. doi: 10.1227/01.NEU.0000368386.85578.63

93. Ruggieri MR, Braverman AS, D’Andrea L, Betz R, Barbe MF. Functional reinnervation of the canine bladder after spinal root transection and genitofemoral nerve transfer at one and three months after denervation. J Neurotrauma. (2008) 25:401-9. doi: 10.1089/neu.2007.0335

94. Ruggieri MR, Braverman AS, Bernal RM, Lamarre NS, Brown JM, Barbe MF. Reinnervation of urethral and anal sphincters with femoral motor nerve to pudendal nerve transfer. Neurourol Urodyn. (2011) 30:1695-704. doi: $10.1002 /$ nau. 21171

95. Blight AR, Toombs JP, Bauer MS, Widmer WR. The effects of 4-aminopyridine on neurological deficits in chronic cases of traumatic spinal cord injury in dogs: a phase i clinical trial. J Neurotrauma. (1991) 8:103-19. doi: 10.1089/neu.1991.8.103

96. Lim JH, Muguet-Chanoit AC, Smith DT, Laber E, Olby NJ. Potassium channel antagonists 4-aminopyridine and the T-butyl carbamate derivative of 4-aminopyridine improve hind limb function in chronically nonambulatory dogs; a blinded, placebo-controlled trial. PLoS ONE. (2014) 9:e116139. doi: 10.1371/journal.pone.0116139

97. Blight AR. Effect of 4-aminopyridine on axonal conduction-block in chronic spinal cord injury. Brain Res Bull. (1989) 22:47-52. doi: 10.1016/0361-9230(89)90126-3

98. Lewis MJ, Laber E, Olby NJ. Predictors of response to 4-aminopyridine in chronic canine spinal cord injury. J Neurotrauma. (2019) 36:1428-34. doi: 10.1089/neu.2018.5975

99. Smith KJ, Felts PA, John GR. Effects of 4-aminopyridine on demyelinated axons, synapses and muscle tension. Brain. (2000) 123:171-84. doi: 10.1093/brain/123.1.171 
100. Muir E, De Winter F, Verhaagen J, Fawcett J. Recent advances in the therapeutic uses of chondroitinase ABC. Exp Neurol. (2019) 321:113032. doi: 10.1016/j.expneurol.2019.113032

101. Hu HZ, Granger N, Balakrishna Pai S, Bellamkonda R V., Jeffery ND. Therapeutic efficacy of microtube-embedded chondroitinase $A B C$ in a canine clinical model of spinal cord injury. Brain. (2018) 141:1017-27. doi: 10.1093/brain/awy007

102. Lee SH, Kim Y, Rhew D, Kuk M, Kim M, Kim WH, et al. Effect of the combination of mesenchymal stromal cells and chondroitinase $\mathrm{ABC}$ on chronic spinal cord injury. Cytotherapy. (2015) 17:1374-83. doi: 10.1016/j.jcyt.2015.05.012

103. Lee JH, Choi CB, Chung DJ, Kang EH, Chang HS, Hwang SH, et al. Development of an improved canine model of percutaneous spinal cord compression injury by balloon catheter. J Neurosci Methods. (2008) 167:3106. doi: 10.1016/j.jneumeth.2007.07.020

104. Lim JH, Jung CS, Byeon YE, Wan HK, Yoon JH, Kang KS, et al. Establishment of a canine spinal cord injury model induced by epidural balloon compression. J Vet Sci. (2007) 8:89-94. doi: 10.4142/jvs.2007.8.1.89

105. Griffiths IR. Vasogenic edema following acute and chronic spinal cord compression in the dog. J Neurosurg. (1975) 42:155-65. doi: 10.3171/jns.1975.42.2.0155

106. Kobrine AI. Blood flow in experimental cord trauma. J Neurosurg. (1979) 50:270-1. doi: 10.3171/jns.1979.50.2.0270

107. Lim JH, Byeon YE, Ryu HH, Jeong YH, Lee YW, Wan HK, et al. Transplantation of canine umbilical cord blood-derived mesenchymal stem cells in experimentally induced spinal cord injured dogs. J Vet Sci. (2007) 8:275-82. doi: 10.4142 /jvs.2007.8.3.275

108. Ryu HH, Kang BJ, Park SS, Kim Y, Sung GJ, Woo HM, et al. Comparison of mesenchymal stem cells derived from fat, bone marrow, Wharton's jelly, and umbilical cord blood for treating spinal cord injuries in dogs. J Vet Med Sci. (2012) 74:1617-30. doi: 10.1292/jvms.12-0065

109. Lee SH, Kim Y, Rhew D, Kim A, Jo KR, Yoon Y, et al. Effect of canine mesenchymal stromal cells overexpressing heme oxygenase-1 in spinal cord injury. J Vet Sci. (2017) 18:377-86. doi: 10.4142/jvs.2017. 18.3.377

110. Park SS, Byeon YE, Ryu HH, Kang BJ, Kim Y, Kim WH, et al. Comparison of canine umbilical cord blood-derived mesenchymal stem cell transplantation times: involvement of astrogliosis, inflammation, intracellular actin cytoskeleton pathways, and neurotrophin-3. Cell Transplant. (2011) 20:1867-80. doi: 10.3727/096368911X566163

111. Lee JH, Chung WH, Kang EH, Chung DJ, Choi CB, Chang HS, et al. Schwann cell-like remyelination following transplantation of human umbilical cord blood (hUCB)-derived mesenchymal stem cells in dogs with acute spinal cord injury. J Neurol Sci. (2011) 300:86-96. doi: 10.1016/j.jns.2010.09.025

112. Ryu HH, Lim JH, Byeon YE, Park JR, Seo MS, Lee YW, et al. Functional recovery and neural differentiation after transplantation of allogenic adiposederived stem cells in a canine model of acute spinal cord injury. J Vet Sci. (2009) 10:273-84. doi: 10.4142/jvs.2009.10.4.273

113. Kim Y, Jo SH, Kim WH, Kweon OK. Antioxidant and anti-inflammatory effects of intravenously injected adipose derived mesenchymal stem cells in dogs with acute spinal cord injury. Stem Cell Res Ther. (2015) 6:229. doi: 10.1186/s13287-015-0236-5

114. Park SS, Lee YJ, Lee SH, Lee D, Choi K, Kim WH, et al. Functional recovery after spinal cord injury in dogs treated with a combination of matrigel and neural-induced adipose-derived mesenchymal Stem cells. Cytotherapy. (2012) 14:584-97. doi: 10.3109/14653249.2012.658913

115. Jung DI, Ha J, Kang BT, Kim JW, Quan FS, Lee JH, et al. A comparison of autologous and allogenic bone marrow-derived mesenchymal stem cell transplantation in canine spinal cord injury. J Neurol Sci. (2009) 285:67-77. doi: 10.1016/j.jns.2009.05.027

116. Khan IU, Yoon Y, Choi KU, Jo KR, Kim N, Lee E, et al. Therapeutic effects of intravenous injection of fresh and frozen thawed ho-1-overexpressed ad-mscs in dogs with acute spinal cord injury. Stem Cells Int. (2019) 2019:8537541. doi: 10.1155/2019/8537541

117. Khan IU, Yoon Y, Kim A, Jo KR, Choi KU, Jung T, et al. Improved healing after the co-transplantation of ho-1 and bdnf overexpressed mesenchymal stem cells in the subacute spinal cord injury of dogs. Cell Transplant. (2018) 27:1140-53. doi: 10.1177/0963689718779766
118. Handa Y, Naito A, Watanabe S, Komatsu S, Shimizu Y. functional recovery of locomotive behavior in the adult spinal dog. Tohoku J Exp Med. (1986) 148:373-84. doi: $10.1620 /$ tjem. 148.373

119. Naito A, Shimizu Y, Handa Y. Analyses of airstepping movement in adult spinal dogs. Tohoku J Exp Med. (1990) 162:41-8. doi: 10.1620/tjem.162.41

120. Kim BG, Kang YM, Phi JH, Kim YH, Hwang DH, Choi JY, et al. Implantation of polymer scaffolds seeded with neural stem cells in a canine spinal cord injury model. Cytotherapy. (2010) 12:841-5. doi: $10.3109 / 14653249.2010 .501784$

121. Lee SH, Chung YN, Kim YH, Kim YJ, Park JP, Kwon DK, et al. Effects of human neural stem cell transplantation in canine spinal cord hemisection. Neurol Res. (2009) 31:996-1002. doi: 10.1179/174313209X3 85626

122. Assina R, Sankar T, Theodore N, Javedan SP, Gibson AR, Horn $\mathrm{KM}$, et al. Activated autologous macrophage implantation in a large animal model of spinal cord injury. Neurosurg Focus. (2008) 25:E3. doi: 10.3171/FOC.2008.25.11.E3

123. Li X, Tan J, Xiao Z, Zhao Y, Han S, Liu D, et al. Transplantation of hUC-MSCs seeded collagen scaffolds reduces scar formation and promotes functional recovery in canines with chronic spinal cord injury. Sci Rep. (2017) 6:43559. doi: $10.1038 /$ srep43559

124. Han S, Xiao Z, Li X, Zhao H, Wang B, Qiu Z, et al. Human placentaderived mesenchymal stem cells loaded on linear ordered collagen scaffold improves functional recovery after completely transected spinal cord injury in canine. Sci China Life Sci. (2018) 61:2-13. doi: 10.1007/s11427-0169002-6

125. Wu GH, Shi HJ, Che MT, Huang MY, Wei QS, Feng B, et al. Recovery of paralyzed limb motor function in canine with complete spinal cord injury following implantation of MSC-derived neural network tissue. Biomaterials. (2018) 181:15-34. doi: 10.1016/j.biomaterials.2018. 07.010

126. El-Kheir WA, Gabr H, Awad MR, Ghannam O, Barakat Y, Farghali HAMA, et al. Autologous bone marrow-derived cell therapy combined with physical therapy induces functional improvement in chronic spinal cord injury patients. Cell Transplant. (2014) 24:1813-27. doi: 10.3727/096368913X664540

127. Kim Y, Lee SH, Kim WH, Kweon OK. Transplantation of adipose derived mesenchymal stem cells for acute thoracolumbar disc disease with no deep pain perception in dogs. J Vet Sci. (2016) 17:123-6. doi: 10.4142/jvs.2016.17.1.123

128. McMahill BG, Spriet M, Sisó S, Manzer MD, Mitchell G, McGee J, et al. Feasibility study of canine epidermal neural crest stem cell transplantation in the spinal cords of dogs. Stem Cells Transl Med. (2015) 4:1173-86. doi: $10.5966 / \mathrm{sctm} .2015-0018$

129. Steffensen N, Lehmbecker A, Gerhauser I, Wang Y, Carlson R, Tipold A, et al. Generation and characterization of highly purified canine schwann cells from spinal nerve dorsal roots as potential new candidates for transplantation strategies. J Tissue Eng Regen Med. (2018) 12:e422-37. doi: 10.1002/term.2478

130. Lim JH, Olby NJ. Generation of pure cultures of autologous schwann cells by use of biopsy specimens of the dorsal cutaneous branches of the cervical nerves of young adult dogs. Am J Vet Res. (2016) 77:1166-74. doi: 10.2460/ajvr.77.10.1166

131. Doucette R. Olfactory ensheathing cells: potential for glial cell transplantation into areas of CNS injury. Histol Histopathol. (1995) 10:503-7.

132. Ramón-Cueto A, Valverde F. Olfactory bulb ensheathing glia: a unique cell type with axonal growth-promoting properties. Glia. (1995) 14:163-73. doi: 10.1002/glia.440140302

133. Fawcett JW. Spinal cord repair: from experimental models to human application. Spinal Cord. (1998) 36:811-7. doi: 10.1038/sj.sc.3100769

134. Franklin RJM, Barnett SC. Olfactory ensheathing cells and CNS regeneration: the sweet smell of success? Neuron. (2000) 28:15-8. doi: 10.1016/S0896-6273(00)00080-5

135. Smith PM, Lakatos A, Barnett SC, Jeffery ND, Franklin RJM. Cryopreserved cells isolated from the adult canine olfactory bulb are capable of extensive remyelination following transplantation into the adult rat CNS. Exp Neurol. (2002) 176:402-6. doi: 10.1006/exnr. 2002.7936 
136. Skinner APC, Pachnicke S, Lakatos A, Franklin RJM, Jeffery ND. Nasal and frontal sinus mucosa of the adult dog contain numerous olfactory sensory neurons and ensheathing glia. Res Vet Sci. (2005) 78:9-15. doi: 10.1016/j.rvsc.2004.05.010

137. Ito D, Fujita N, Ibanez C, Sasaki N, Franklin RJM, Jeffery ND. Serumfree medium provides a clinically relevant method to increase olfactory ensheathing cell numbers in olfactory mucosa cell culture. Cell Transplant. (2008) 16:1021-7. doi: 10.3727/000000007783472345

138. Wewetzer K, Radtke C, Kocsis J, Baumgärtner W. Species-specific control of cellular proliferation and the impact of large animal models for the use of olfactory ensheathing cells and Schwann cells in spinal cord repair. Exp Neurol. (2011) 229:80-7. doi: 10.1016/j.expneurol.2010.08.029

139. Ito D, Carwardine D, Prager J, Wong LF, Kitagawa M, Jeffery N, et al. Methods of olfactory ensheathing cell harvesting from the olfactory mucosa in dogs. PLoS ONE. (2019) 14:e0213252. doi: 10.1371/journal.pone. 0213252

140. Andrews PJ, Poirrier AL, Lund VJ, Choi D. Safety of human olfactory mucosal biopsy for the purpose of olfactory ensheathing cell harvest and nerve repair: a prospective controlled study in patients undergoing endoscopic sinus surgery. Rhinol J. (2016) 54:183-191. doi: 10.4193/Rhin 15.365

141. Li Y, Field PM, Raisman G. Repair of adult rat corticospinal tract by transplants of olfactory ensheathing cells. Science. (1997) 277:2000-2. doi: $10.1126 /$ science.277.5334.2000

142. Franklin RJM, Gilson JM, Franceschini IA, Barnett SC. Schwann cell-like myelination following transplantation of an olfactory bulb-ensheathing cell line into areas of demyelination in the adult CNS. Glia. (1996) 17:217-24. doi: 10.1002/(SICI)1098-1136(199607)17:3<217::AID-GLIA4>3.0.CO;2-Y

143. Granger N, Blamires H, Franklin RJM, Jeffery ND. Autologous olfactory mucosal cell transplants in clinical spinal cord injury: a randomized doubleblinded trial in a canine translational model. Brain. (2012) 135:3227-37. doi: 10.1093/brain/aws268

144. Carwardine D, Prager J, Neeves J, Muir EM, Uney J, Granger N, et al. Transplantation of canine olfactory ensheathing cells producing chondroitinase $\mathrm{ABC}$ promotes chondroitin sulphate proteoglycan digestion and axonal sprouting following spinal cord injury. PLOS ONE. (2017) 12:e0188967. doi: 10.1371/journal.pone.0188967

145. Nishida H, Nakayama M, Tanaka H, Kitamura M, Hatoya S, Sugiura $\mathrm{K}$, et al. Safety of autologous bone marrow stromal cell transplantation in dogs with acute spinal cord injury. Vet Surg. (2012) 41:437-42. doi: 10.1111/j.1532-950X.2011.00959.x

146. Tamura K, Harada Y, Kunimi M, Takemitsu H, Hara Y, Nakamura T, et al. Autologous bone marrow mononuclear cell transplant and surgical decompression in a dog with chronic spinal cord injury. Exp Clin Transplant. (2015) 13:100-5. doi: 10.6002/ect.2013.0237

147. Penha EM, Meira CS, Guimarães ET, Mendonça MVP, Gravely FA, Pinheiro $\mathrm{CMB}$, et al. Use of autologous mesenchymal stem cells derived from bone marrow for the treatment of naturally injured spinal cord in dogs. Stem Cells Int. (2014) 2014:437521. doi: 10.1155/2014/437521

148. Sarmento C, Rodrigues M, Bocabello R, Mess A, Miglino M. Pilot study: bone marrow stem cells as a treatment for dogs with chronic spinal cord injury. Regen Med Res. (2014) 2:9. doi: 10.1186/2050-490X-2-9

149. Escalhão CCMI, Ramos IP, Hochman-Mendez C, Brunswick THK, Souza SAL, Gutfilen B, et al. Safety of allogeneic canine adipose tissue-derived mesenchymal stem cell intraspinal transplantation in dogs with chronic spinal cord injury. Stem Cells Int. (2017) 2017:3053759. doi: 10.1155/2017/3053759

150. Bach FS, Rebelatto CLK, Fracaro L, Senegaglia AC, Fragoso FYI, Daga $\mathrm{DR}$, et al. Comparison of the efficacy of surgical decompression alone and combined with canine adipose tissue-derived stem cell transplantation in dogs with acute thoracolumbar disk disease and spinal cord injury. Front Vet Sci. (2019) 6:383. doi: 10.3389/fvets.2019.00383

151. Feitosa MLT, Sarmento CAP, Bocabello RZ, Beltrão-Braga PCB, Pignatari GC, Giglio RF, et al. Transplantation of human immature dental pulp stem cell in dogs with chronic spinal cord injury. Acta Cir Bras. (2017) 32:540-9. doi: 10.1590/s0102-865020170070000005

152. Besalti O, Aktas Z, Can P, Akpinar E, Elcin AE, Elcin YM. The use of autologous neurogenically-induced bone marrow-derived mesenchymal stem cells for the treatment of paraplegic dogs without nociception due to spinal trauma. J Vet Med Sci. (2016) 78:1465-73. doi: 10.1292/jvms.15-0571

153. Bhat IA, Sivanarayanan TB, Somal A, Pandey S, Bharti MK, Panda BSK, et al. An allogenic therapeutic strategy for canine spinal cord injury using mesenchymal stem cells. J Cell Physiol. (2019) 234:2705-18. doi: $10.1002 /$ jcp. 27086

Conflict of Interest: The authors declare that the research was conducted in the absence of any commercial or financial relationships that could be construed as a potential conflict of interest.

Copyright (c) 2020 Lewis, Granger, Jeffery and the Canine Spinal Cord Injury Consortium (CANSORT-SCI). This is an open-access article distributed under the terms of the Creative Commons Attribution License (CC BY). The use, distribution or reproduction in other forums is permitted, provided the original author(s) and the copyright owner(s) are credited and that the original publication in this journal is cited, in accordance with accepted academic practice. No use, distribution or reproduction is permitted which does not comply with these terms. 